\title{
FOREWORD
}

\section{Lessons for Indonesia from East Asia}

I am pleased to be able to write the Foreword for this important and timely book on the Indonesian economy. As we know the country is currently entering the five-yearly elections cycle that will set the political stage for the subsequent five years.

The book aims to shed light on whether Indonesia has presently embarked on a new development model. In this piece I would like to share with you my reflection, inevitably quite subjective, on a related but somewhat narrower issue. The question I am going to raise is what Indonesia could learn from the experience of the East Asian countries. I will relate it to the changing environment of policymaking in Indonesia in the past six decades or so, half of which time I had had the privilege to observe the process from the ring side, so to speak, and subsequently found myself increasingly drawn into the ring. I will conclude with a tentative suggestion on how Indonesia could improve its policy performance in the coming years.

Let me begin by clarifying what I mean by the East Asian countries. In this group I include Japan, Taiwan, South Korea, Singapore, Hong Kong and, more recently, China and now perhaps also Vietnam. This group in my view is unique because in their quest for development they carried out similar strategies with similar outcomes.

I am aware that within that group individual countries differ in their experiences and in their specific policies with regard to their important sectors such as industries, trade and finance. Nonetheless, we can readily identify some basic commonalities in their approaches to development. For the purpose of this talk I will pick two of them. 
The first is this. From the early stages of their development these countries consistently placed high in their agenda the upgrading of three strategic areas, namely, education, bureaucracy and infrastructure. The first two - education and bureaucracy - have roots in the Confucian precept about the basic role of the state, while the third is an enabling element. The pursuit of these three objectives constitutes a crucial part of their development stories.

Their strategy emphasizes the "supply side" development with the goal of progressively raising the country's "productive capacity". In the literature three factors, namely, human resources, institutions and infrastructure, have consistently stood out as prime determinants of a country's development in the long run. The success of the East Asian countries with their strategy corroborates this view.

I am raising the issue of long-term productivity and supply to highlight what I see as an apparent lop-sidedness of policy discussions and policy practice in Indonesia, especially in the past twenty years or so (my time in government not excepted). By default or by design they tend to be dominated by short-term issues and are too demand-oriented. For example, when policymakers talk about growth, more likely than not the focus is on how to raise it this year or the next and the way to do that is primarily by juggling the components of aggregate demand or spending, almost taking for granted the supply side. Such a mode of thinking - appropriate for market analysts but grossly inadequate for development policymakers - when it translates into policy practice would inevitably have far-reaching consequences. The fault, though, seems to lie not so much in the policymakers as in the politics of the country. We will come back to this issue, but presently let me say a bit more about those three factors.

To raise the quality of a country's human resources over the long run, the law of population dynamics requires us to focus on taking care of our children and youth - the next generation. The principal instrument for it is a fully integrated, well-targetted education-cum-health intervention scheme applied to all children right from their earliest ages through their teens. The key words here are fully integrated and well-targetted.

The East Asian focus on creating an effective bureaucracy is an important lesson. Too often we hear how bureaucracy has often become a drag on, rather than a prop of, development. Yet too few countries have seriously and systematically carried out the all-important task of reforming 
their bureaucracies. In reality the task is much greater than reforming government bureaucracy. To sustain the impacts, other important public institutions, among which the legal institutions are the most critical, must be concurrently reformed.

Being more tangible, building the third element of the "trilogy" physical infrastructures - should be a more straightforward task. But even here a clearer statement of priorities is imperative. What we want to build is not just a collection of unrelated pieces of infrastructure but effective networks of infrastructure that jointly serve: (a) to raise the general productivity of, and lower the transaction costs across, the economy; (b) to support the other two objectives (human resources and institutional development); and (c) very importantly for young nations, to integrate various parts of the economy into a more unified national entity. A good plan of infrastructures development must therefore contain a strategic vision of the needed infrastructure networks in, say, the next twenty to thirty years.

Pursuing with resolve and efficiency that trilogy of development is a clear lesson that Indonesia could learn from the East Asian experience.

The second feature of the East Asian experience does not provide a ready guide for action but it is an important lesson nonetheless. It relates to the choice of policy frameworks and the supporting institutional setup. The East Asian countries decided right from the outset to adopt some sort of "corporatist" model in which business enterprises continued to be relied on as the main actors in the economy, while the state assumed a strong and active coordinating and guiding role.

In their case such an approach required a bureaucracy and political system that enabled the state to discharge its activist role. That is why, at the early stages of their development, necessarily their bureaucracies tended to operate in the top-down mode and their political regimes were not democratic. It was only at later stages of their development that some of those countries began to embrace full democracy and a less rigid bureaucracy.

The important thing to note is that during the critical stages of their development they were freed from the problem of "shortermism" that often afflicts democracies, especially the young ones. Their strategic plans were somehow spared from the vagaries of discontinuities and abrupt swings that often follow election cycles. Political gridlocks that cause delays and indecision in policymaking did not appear to be their main problem. They 
therefore could better channel their administrative and social energies into solving long-term issues that really matter for development. True, the journeys of the East Asian countries were far from smooth sailing. Mistakes were made and social and economic costs, often quite substantial, were incurred. But the bottom line is that somehow the essential foundations for their sustained development got built.

We may note that Indonesia in fact had its own experience with a similar regime, with a slightly different twist. More than three decades under the New Order, Indonesia had witnessed significant progress on its economic and social fronts, thanks to the implementation of systematic development policies overseen by a group of capable and dedicated technocrats working under the umbrella of a not quite democratic but stable political regime. Progress begets new aspirations. As living conditions improved the calls among the populace for greater say and participation in politics became increasingly vocal. There was also a growing perception that rent-seeking activities and corruption among the elite had been growing unchecked.

Alas, the needed political reforms never came. The 1997/98 financial crisis provided a trigger for the subsequent social and political upheavals that eventually led to a regime change. The Reformasi reinstated a full electoral democracy, the separation of state powers, the system of checks and balances in government and free press. But on the more operational levels something important is lost. A group of dedicated technocrats overseeing policies is no more, and the established mode ensuring continuity of policies over time has vanished.

That is the general picture. Let us now delve a little deeper.

In terms of human resources development, the New Order had recorded a quantum leap in education and health areas, at least compared with the situation at the beginning of the era. However, the 1997/98 crisis had caused a serious setback in these sectors, only to recover very slowly thereafter. The population and technological dynamics have made the task we are facing now weightier by the day. In the midst of the current technological revolution the Indonesian labour force is still dominated by unskilled labour. On the quality of school education, international surveys have consistently placed Indonesia well behind any of the East Asian countries. And despite all the efforts the percentage of stunted children remains the highest in the region. These are just a few facts that should serve as a compelling reminder that more resources, better planning and 
execution and above all stronger political commitment are desperately needed to do the big catching up.

The second element of the trilogy has not fared any better. I have to say that the New Order institutional development has never been given the weight it deserves. Efforts to reform the bureaucracy have been patchy. It is not so much a lack of ideas as a lack of sustained commitment to systematically implement them. Evidence keeps emerging that important parts of the central and regional government bureaucracies act more as a drag on development. In the progress in legal reform there is also still much to be desired.

The records of infrastructure development are somewhat better. During the New Order, wide-ranging infrastructures were built and the standards of infrastructure services in Indonesia were on par with its neighbours in the region. But again the crisis of 1997/98 had brought about a collapse in infrastructure spending which as percentage of GDP has not recovered to its New Order level to this day. We should duly recognize, though, the serious efforts by the present administration to accelerate infrastructure development.

It has been two decades now since Indonesia first launched its Reformasi. The pertinent question to be asked is whether a democratic polity as we currently have could and would evolve to be one that supports higher gear development. For many of us, the preferred answer is likely to be yes. As hopeful as we might be, though, it is important to keep our feet on the ground. We should constantly remind ourselves of the following basic truths: that democracy per se does not guarantee development, that development can only come from rising long-term productivity, that longterm productivity is determined by the quality of the nation's human resources, its public institutions and its networks of infrastructure, and also we must never forget that without development democracy itself is unlikely to survive.

What we need is a "development-oriented" democracy. One that is not merely understood as a competitive game of acquiring power but also one that is animated by collective consciousness and higher desire to achieve common progress. A democracy that is not hostage to "shortermism". One that can produce and execute a rational blueprint for the nation's long-term development. A democracy that is not saddled with gridlocks, delays and indecision. A democracy that delivers results. Such a democracy, or a close approximation of it, is indeed possible. But, just to remind ourselves, the 
onus falls on those who have faith in democracy to make such a regime a living reality. If history is any guide, the journey would likely be long and challenging, requiring constancy of purpose and a reservoir of collective wisdom to maintain the delicate balance between freedom and order along the way.

As we travel along that road, we will be faced with the practical question: what should we do while our democracy is still in the process of consolidation? Given the state where we are now, let me try out some very preliminary thoughts on the issue in the hope that they will spark discussions and, who knows, perhaps also actions.

First, adopt the trilogy as the overarching theme of the national development efforts. Prepare a strategic blueprint for the three components, taking a planning horizon of, say, twenty years to come. Prepare a more specific plan of actions for its first ten years and fully worked-out programmes for its first five years. This last-mentioned part of the plan should in principle be ready for execution by the new Cabinet on its first day in office.

That constitutes the base plan. On top of that we may add whatever other themes (such as policies on industry, trade, finance, social welfare and national security) deemed necessary to make the blueprint a more complete development plan. Needless to say, the plan must be of first-rate quality, not just another bureaucratic product, as it serves as the main conduit for reintroducing the essential elements of effective policies that have been lost, namely, order, focus, coherence, rationality and continuity.

You may also need a radical restructuring of the Cabinet. There may be seven coordinating ministers corresponding to seven areas of responsibilities: human development, bureaucratic reform, legal reform, infrastructure development, social welfare, economic-cum-finance, and national security. Each coordinating minister is "field commander" with the sole mission of making the goals in his or her area of responsibility a reality. Sufficient coordinating power and perhaps also some line authorities should be vested with the coordinating ministers to enable them to optimally mobilize the relevant operational ministers to help achieve those goals. Unlike the current set-up, the main job of operational ministers is to implement policies as directed by the coordinating ministers, not to contrive their own goals and policies. 
There is one more thing. Our own experience and that of other countries confirm that some sort of institutionalized mechanism of control, that independently and objectively evaluates the execution of policies on the ground and directly reports to the President, is indispensable. Alas, this matter is too often not given its due weight at the cost of performance.

Finally, here is an almost redundant reminder: the proposed scheme will come to naught if the strategic slots are not filled with persons who know their jobs and know how to get the jobs done through teamwork.

By now some of you may be wondering why such a top-down scheme. The scheme may be thought to be appropriate for an authoritarian regime with central planning but not for a democracy which cherishes initiatives and participation of its citizens. My whole narrative is meant to underscore the importance of what have been missing in policymaking in this country, namely: order, focus, coherence, rationality and continuity. They are absolutely crucial for effective conduct of policies in any political system, be it a democracy or not. When missing, they must somehow be rewired into the system lest the country diminish into Socrates' proverbial ship that is forever condemned to go adrift in the open sea.

Boediono

Former Vice-President of Indonesia 